19 Revue d'histoire du XIXe siècle

Société d'histoire de la révolution de 1848 et des

révolutions du XIXe siècle

$24 \mid 2002$

Varia

Images de l'enfance et de la jeunesse "irrégulières"

Le Temps de l'histoire, $\mathrm{n}^{\circ}$ 4, juin 2002, 252 p.

Jean-Claude Farcy

(2) OpenEdition

Journals

Édition électronique

URL : http://journals.openedition.org/rh19/386

DOI : $10.4000 /$ rh19.386

ISSN : $1777-5329$

Éditeur

La Société de 1848

Édition imprimée

Date de publication : 1 juin 2002

Pagination : 184-186

ISSN : 1265-1354

Référence électronique

Jean-Claude Farcy, "Images de l'enfance et de la jeunesse "irrégulières" », Revue d'histoire du XIXe siècle

[En ligne], 24 | 2002, mis en ligne le 04 juin 2003, consulté le 22 septembre 2020. URL : http://

journals.openedition.org/rh19/386 ; DOI : https://doi.org/10.4000/rh19.386

Ce document a été généré automatiquement le 22 septembre 2020.

Tous droits réservés 


\section{Images de l'enfance et de la jeunesse "irrégulières"}

Le Temps de l'histoire, $\mathrm{n}^{\circ} 4$, juin 2002, $252 \mathrm{p}$.

Jean-Claude Farcy

Les lecteurs de notre revue, qui a déjà consacré plusieurs articles à l'histoire de l'enfance et de la jeunesse, seront particulièrement intéressés par le dernier numéro du Temps de l'histoire, publié par la jeune Association pour l'histoire de l'éducation surveillée et de la protection judiciaire de la jeunesse et consacré aux images de l'enfance et de la jeunesse dites "irrégulières". Outre plusieurs articles analysant les représentations de la délinquance juvénile du second $\mathrm{XX}^{\mathrm{e}}$ siècle à la télévision (on note la réticence à traiter des blousons noirs dans les années 1960) ou sur le grand écran, les spécialistes du XIX ${ }^{e}$ siècle apprécieront deux textes, tous deux très stimulants, sur l'image du gamin de Paris et sur les origines du terme Apache associé aux turbulences de la jeunesse parisienne des années 1900.

Le premier, sous la plume de Jean-Jacques Yvorel ("De Delacroix à Poulbot. L'image du gamin de Paris") suit la naissance, l'évolution et les diverses facettes d'un type social à travers les textes et l'iconographie. Il date sa première apparition de la révolution de juillet 1830 avec le célèbre tableau de Delacroix (La Liberté guidant le peuple, 1830) associant, dans la tradition des enfants héros de la Grande Révolution (Bara, Viala) deux des traits majeurs du gamin : l'origine populaire et la participation aux révolutions. Le contenu de cet archétype se construit dans les productions culturelles de tous types avec "un jeu d'emprunts et de renvois" que l'auteur qualifie "d'intermédiatique". Enfant du peuple -- le vêtement est un bon marqueur de classe dans l'iconographie--, joueur et moqueur, arpentant le pavé parisien (il est toujours représenté au dehors et jamais au travail), l'enfant des rues indiscipliné est généreux et courageux (Jean-François-Albert Bayard, Émile Vanderbruch, Le gamin de Paris, vaudeville à succès), mais, comme il participe aux barricades (héroïsation hugolienne avec la figure de Gavroche), il est aussi le "symbole du vice", sentinelle avancée des classes dangereuses pour les conservateurs, et cela dès 1831 (Le pâle voyou, d'Auguste Barbier) quand on prend conscience que les journées de Juillet ont ouvert la boîte de Pandore des insurrections et émeutes ouvrières. Si la vision négative l'emporte dans la 
littérature, il semble --mais le corpus d'illustrations analysées ne prétend pas à l'exhaustivité-- que le côté lumière l'emporte dans l'iconographie. Après la Commune, l'image du gamin de Paris s'abâtardit, se folklorise et sert à des fins publicitaires ou pour justifier la politique coloniale. L'encadrement de l'enfance mis en place par la Troisième République modifie les représentations : le gosse des rues, s'il garde des traits de son ancêtre (extraction populaire, insolence, esprit de révolte comme on le voit dans les croquis Poulbot) est d'abord un enfant pauvre, victime d'un milieu familial que les autorités s'attachent à discipliner. Et le nouveau péril va venir désormais de ceux que l'école n'intègre pas : les adolescents des couches populaires qui inquiètent tant dans le Paris de la Belle époque.

Dominique Kalifa éclaire parfaitement les origines du terme que les contemporains vont utiliser pour stigmatiser cette jeunesse rebelle ("Archéologie de l'Apachisme. Les représentations de Peaux-Rouges dans la France du XIXe siècle") en montrant que trois grandes périodes sont à relever dans l'intérêt porté au monde indien. La première, dans les années 1827-1831, se traduit à la fois par l'engouement pour les romans de Fenimore Cooper et par l'assimilation des prolétaires à des hordes sauvages, barbares, assimilation dont on trouvera l'écho chez Balzac, Tocqueville ou Eugène Sue. Le rêve de la conquête mexicaine, sous l'Empire libéral, constitue la seconde étape : c'est la découverte véritable des Apaches, perçus comme un obstacle au programme de conquête, et présentés comme des sauvages cruels et sanguinaires, rebelles à toute civilisation, incarnant le dernier degré de la sauvagerie, alors que les Comanches sont présentés comme assimilables. Les romans indiens à succès de cette époque --les principaux auteurs en sont Gabriel Ferry et Gustave Aimard-- popularisent cette image de l'Apache rebut de l'espèce humaine, ce qui justifie son élimination. Les dernières guerres indiennes des années 1880 , menées notamment contre les tribus apaches de Geronimo, sont l'occasion de parachever le portrait à charge de ces sauvages hostiles, tel qu'on peut le lire, par exemple, sous la plume de l'ethnologue Élie Reclus. On comprend dès lors que voyous et rôdeurs des bas-fonds de la capitale aient été très tôt assimilés aux Indiens, et cela dès le milieu du XIX ${ }^{e}$ siècle. Dans les Peaux-Rouges de Paris de Gustave Aimard (1888), les malfrats ont la même immoralité, la même sauvagerie, le même exotisme (mœurs, argot, tatouages...). De plus, comme le remarque Dominique Kalifa en spécialiste de ce sujet, l'ouvrage illustre bien l'émergence du roman de détection par le biais de l'analogie entre le monde de la forêt (et de la chasse) et la quête des traces dans la grande ville. Pour ces jeunes délinquants, étudiés pour la première fois par Michelle Perrot dans le prolongement de la contestation estudiantine de 1968, la revendication d'une filiation avec les tribus indiennes traduit une dissidence, un rejet des valeurs de la société industrielle, mais aussi l'absence de perspectives et la plus ou moins claire conscience d'un combat sans issue. Pour les élites, la stigmatisation de la révolte juvénile peut s'inscrire dans une logique d'élimination, dès lors qu'elle permet de l'isoler d'un peuple "civilisé" et intégré à la société bourgeoise. L'auteur replace, à juste titre, l'évolution de la figure de l'Apache dans les "stratégies d'intégration des classes inférieures que l'Empire libéral puis la jeune République, s'efforcent de promouvoir. Rien de tel, en effet, pour décriminaliser la menace ouvrière, que de la fragmenter en isolant de l'ensemble, désormais moralisé et acquis aux valeurs et normes de la société moderne, ces tribus dissidentes et irrécupérables qu'il ne restera bientôt plus qu'à éliminer par le bagne et par la guillotine" (p. 31).

On le constate : tout l'intérêt de ces deux articles est d'articuler l'analyse des représentations à l'histoire sociale. L'autre mérite, mais point n'est besoin de 
développer, est l'actualité de ce numéro du Temps de l'histoire : des Apaches d'il y a un siècle aux "sauvageons" d'aujourd'hui... chacun pourra mesurer combien la stigmatisation des jeunes révoltés ne fait guère avancer les solutions au problème de l'intégration des jeunes générations dans les périodes de mutations ou de crise profonde d'une société. 